\title{
Leveuf: A Rescue Technique after the Failure of Other Hypospadias Techniques
}

\author{
Nabil Jakhlal*, Youness Khdach, Harrison Sumba, Tariq Karmouni, Khalid El Khader, Abdellatif Koutani and \\ Ahmed Iben Andaloussi
}

Department of Urology, Mohammed V University, Morocco

Submission: May 18, 2018; Published: July 06, 2018

*Corresponding author: Nabil Jakhlal, Department of Urology B, Ibn Sina Hospital, Faculty of Medicine and Pharmacy, Mohammed V University, Rabat, Morocco, Tel: 212615327218; Email: doc.nabil54@gmail.com

\begin{abstract}
The patient care of adults who have had complications of primary surgery of hypospadias remains atherapeutic challenge. These patients can be divided into three categories. We report a case of ypospadias that we classify in the second group and for which we opted for a Leveuf urethroplasty with a satisfactory result.

Keywords: Hypospadias; Complication; Management; Leveuf; Ypospadias; Urethroplasty; Vascularized tissues; Aesthetic deformation; Psychosexual; Urethrocutaneous fistula; Persistent bend; Urethral diverticulum; Urethral stricture; Crippled hypospadias; Mucosal ectropion; Mucosal ectropion; Glandular dehiscence; Urethral lithiasis; Urethral plate; Mucosal graft

Abbreviations: UP: Urethral Plate; OM: Oral Mucosal Graft
\end{abstract}

\section{Introduction}

The patient care of adults who have had complications of primary surgery of hypospadias remains a therapeutic challenge. They are undoubtedly a difficult population to treat because these usually include the presence healed and poorly vascularized tissues, aesthetic deformation, lower urinary tract symptoms resulting into psychosexual consequences.These patients can be divided into three categories: the first group are the primary cases, the second group includes patients who had previous surgery during childhood and have a late complication (for example, a urethrocutaneous fistula, a persistent bend, urethral stricture,urethral diverticulum and poor aesthetic result), and the third group are patients who have undergone several failed surgeries called "crippled hypospadias" [1]. We report a case of hypospadias that we classify in the second group and for which we opted for a Leveuf urethroplasty.

\section{Observation}

A 27-year-old patient with a history of failure of primary surgery for hypospadias at the age of 5, who consults for management of this malformation. Physical examination revealed a proximal hypospadias (penoscrotal orifice) with an estimated curvature of $60{ }^{\circ} \mathrm{C} .0 u r$ treatment consisted firstly of straightening of the penis with dorsal plication of corpora cavernosa according to Nesbit. Subsequently, the patient was operated for Leveuf urethroplasty in two stages, a first burial time, and a second release time of the penis from the scrotum (Figure 1\&2). An interval of 7 months took place between the two Leveuf periods. The post-operative evolution was favorable with a decline of 6 months.

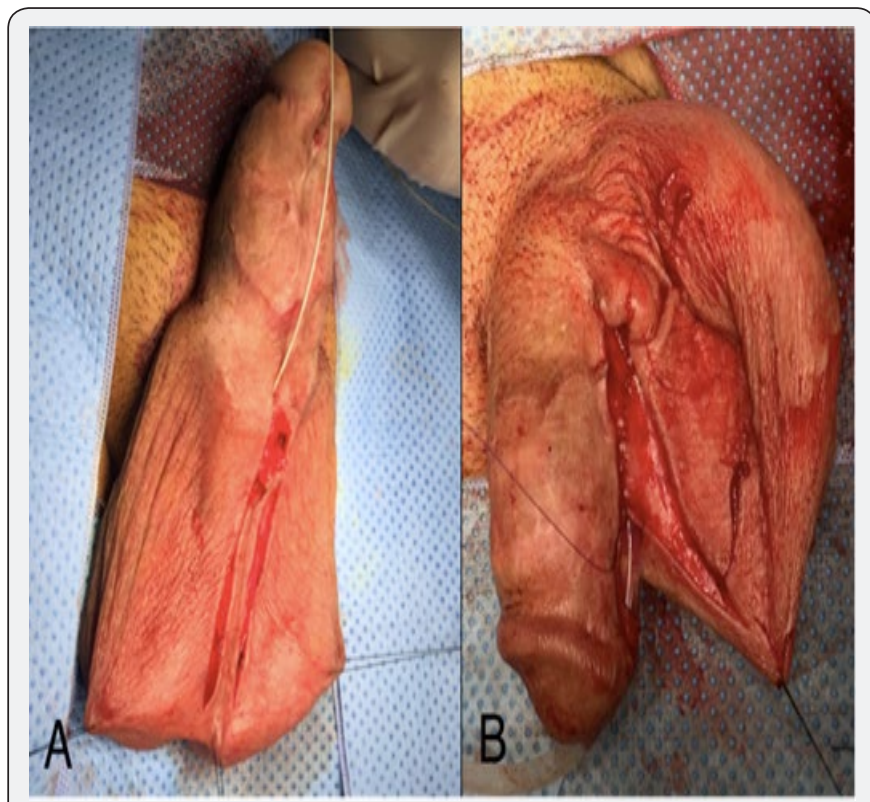

Figure 1: First time of Leveuf. A) U-shaped incision in the scrotum, B) burial of the penis in the scrotum. 


\section{Global Journal of Reproductive Medicine}

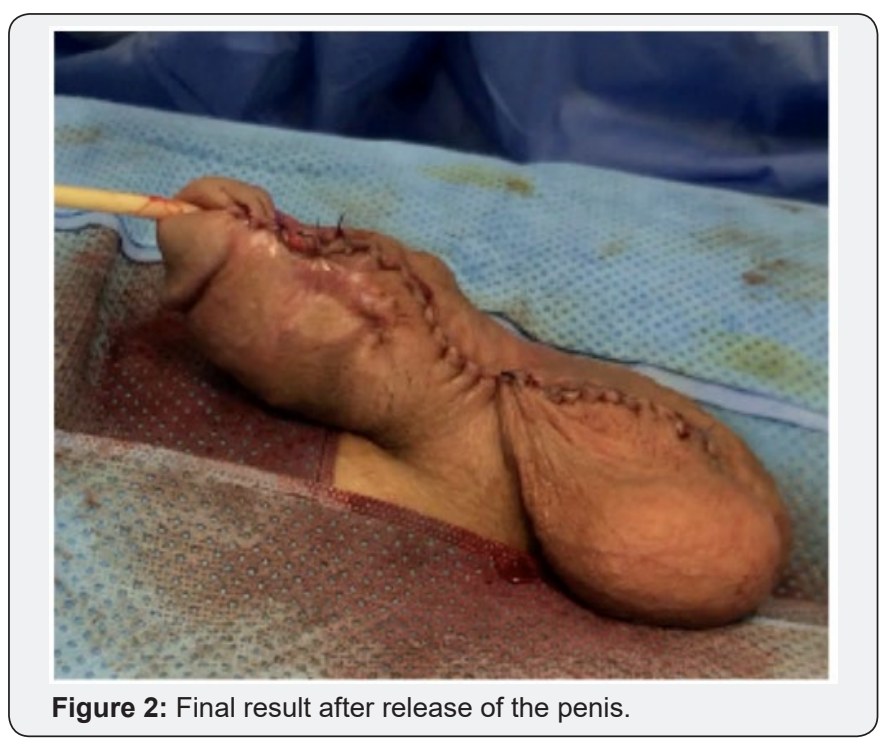

\section{Discussion}

Hypospadias surgery complications include fistulas of the urethra, strictures of the meatus and urethra, glandular dehiscence, curvature persistence, mucosal ectropion, urethrocele, xerotica obliterans balanitis (sclero-atrophic lichen), hairs and urethral lithiasis, multi-operated hypospadias [2]. The complication rate of primary surgery is between 6 and 30\% [3]. It is variable depending on the anomaly and the technique used. Operative failures may result from wound infection, urinary extravasation, hematoma, ischemia and flap and graft necrosis or errors in the technique and postoperative care during primary repair surgery $[4,5]$.

A patient with a defective hypospadias repair would have a more densely scarred penis in adulthood with less vascularized and less malleable tissue [5]. Therefore, repeated attempts for surgical repair in these complicated cases are less likely to succeed. This is evident in a study by Hensle et al. [6] in a group of adult patients with hypospadias repair, complications were noted in $37.5 \%$ of patients without previous surgery, $41.67 \%$ of patients having had one or more interventions in childhood, but in which the local tissue was relatively intact, and $63.6 \%$ of patients who underwent several unsuccessful hypospadias repairs with varying degrees of deformation of the penis and loss of local tissue.Whatever the cause of the reconstruction failure, the principles of the surgical revision remain identical to those of the first surgery.

The three essential stages of this surgery are [7]:

I. Assessment and correction of a residual curvature: Excision of fibrosis to release any curvature and excision of scar tissue, which may include some, or even entire length of previous urethroplasty with any surrounding fibrous tissue. This often leads to a proximal migration of the urethral meatus. If the curvature persists after dissection of the ventral radius, then a dorsal plication of the corpora cavernosa is indicated $[8,9]$.

II. Resumption of urethroplasty: An adequate glans cleft is created with the insertion of a graft or flap. The creation of a neo-urethra and reconstruction of the glans can be done in one or more operating times. If proximal hypospadias and requiring extensive reconstruction with defect of the penile skin, it is best to proceed in two stages with subsequent closure usually within an average of 4-6 months.

III. The reconstruction of the ventral side of the penis: this step should include a tight closure of the neo-urethra with good coverage by a vascularized overlying tissue. In particular, care is taken not to overlap the suture planes to reduce the risk of fistula.

There is no standard urethroplasty technique in this type of surgery. In a sequence of surgical resumption of hypospadias in children, a surgical decision algorithm was based on the presence or absence of an elastic urethral plate (UP): When the UP did not have a visible scar, a TIP procedure (tubularized incised plate) was performed. If the UP was previously excised but a skin band without a visible scar remained at its location, a single-step inlay graft was used. When UP, residual skin or neourethra were visibly healed or there was a persistent ventral curvature greater than $30^{\circ} \mathrm{C}$, hair in the neo-urethra or suspicion of xerotica obliterans balanitis, all largely abnormal tissues were excised up to the healthy urethra, and secondly, urethroplasty by oral mucosal graft (OM) was performed [10].

In majority of resumption cases, the foreskin is no longer available and the penile skin is poorly vascularized, consequently urethroplasty by a local scrotal flap or an oral mucosal graft would be preferable. Unlike flaps, grafts are easier to harvest and sufficiently available but depend on the subject to hold. This emphasizes the importance of vascularization of the bed of the graft. Bürger et al. [11] described the use of OM in recovery operations after failure of hypospadias surgery in 6 patients and reported good functional results in all patients. Since then, several articles have been published on the use of OM grafts in one or more times [12], including Fichtner et al. [13] and Metro et al. [14] who reported complication rates of 20 and $57 \%$ respectively. The scrotal skin can be used in different ways, usually in several stages: as the roof of the urethroplasty according to Leveuf technique [15], or as a cover of the neourethra according to Cecil-Culp $[16,17]$. These techniques could be useful tools in case of deficient of the penile skin and in reducing the formation of fistula $[18,19]$.

\section{Conclusion}

The first step in the care of patients who have had complications of primary hypospadias surgery is the vigilant evaluation of each patient, the anatomical features and the material available to initiate the reconstruction. Leveuf is a technique that could be useful in case of deficient penile skin and to reduce the formation of fistula. However, it is important 
for the surgeon to know about the pros and cons of all routine procedures and that this type of reconstruction should only be performed in highly specialized centers.

\section{References}

1. Howe AS, Hanna MK (2017) Management of 220 adolescents and adults with complications of hypospadias repair during childhood. Asian J Urol 4(1): 14-17.

2. Keating MA, Duckett JW (1995) Failed hypospadias repair. In: Cohen MS, Resnick MI, et al. (Eds) Reoperative Urology, Boston: Little, Brown and Company, USA, pp. 187-204.

3. Bhat A, Mandal AK (2008) Acute postoperative complications of hypospadias repair. Indian J Urol 24(2): 241-248.

4. Devine CJ, Franz JP, Horton CE (1978) Evaluation and treatment of patients with failed hypospadias repair. Trans Am AssocGenitourin Surg 69: 4-7.

5. Stecker JF, Horton CE, Devine CJ, McCraw JB (1981) Hypospadias cripples. Urol Clin North Am 8(3): 539-544.

6. Hensle TW, Tennenbaum SY, Reiley EA, Pollard J (2001) Hypospadias repair in adults: adventures and misadventures. J Urol 165(1): 77-79.

7. Mouriquand PD, Persad R, Sharma S (1995) Hypospadias repair: Current principles and procedures. Br J Urol 76(3): 9-22.

8. Barbagli G, Palminteri E, Lazzeri M, Guazzoni G, Turini D (2001) Long-term outcome of urethroplasty after failed urethrotomy versus primary repair. J Urol165(6): 1918-1919.

9. Nesbitt RM (1965) Congenital curvature of the phallus: Report of three cases with description of corrective operation. J Urol 93: 230-232.
10. Snodgrass WT, Bush N, Cost N (2009) Algorithm for comprehensive approach to hypospadias reoperation using 3 techniques. J Urol 182(6): 2885-2891.

11. Bürger RA, Müller SC, El-Damanhoury H, Tschakaloff A, Riedmiller H, et al. (1992) The buccal mucosal graft for urethral reconstruction: a preliminary report. J Urol 147(3): 662-664.

12. Ding J, Li Q, Li S, Li F, Zhou C, et al: (2014) Ten years' experience for hypospadias repair: combined buccal mucosa graft and local flap for urethral reconstruction. Urol Int 93(4): 454-459.

13. Fichtner J, Filipas D, Fisch M, Hohenfellner R, Thüroff JW (1970) Longterm follow-up of buccal mucosa onlay graft for hypospadias repair: analysis of complications. J Urol172(5 Pt 1): 1970-1972.

14. Metro MJ, Wu HY, Snyder HM, Zderic SA, Canning DA (2001) Buccal mucosal grafts: lessons learned from an 8-year experience. J Uro 166(4): 1459-1461.

15. Leveuf J (1946) Le traitement de l'hypospadias. Journal de Chirurgie 62: 90-98.

16. Cecil AB(I946)Repair of hypospadias and urethral fistula. Journal of Urology 50: e37-24z.

17. Culp OS (1951) Early correction of congenital chordee and hypospadias. J Urol 65(2): 264-278

18. Farina R (1972) Surgical treatment of hypospadias: experience in the treatment of 400 consecutive cases using Leveuf's technique.Br J Plast Surg 25(2): 180-188.

19. HadidiAT (2004) Hypospadias Surgery. Springer-Verlag Berlin Heidelberg.

\section{Your next submission with Juniper Publishers will reach you the below assets}

- Quality Editorial service

- Swift Peer Review

- Reprints availability

- E-prints Service

- Manuscript Podcast for convenient understanding

- Global attainment for your research

- Manuscript accessibility in different formats

( Pdf, E-pub, Full Text, Audio)

- Unceasing customer service

Track the below URL for one-step submission https://juniperpublishers.com/online-submission.php 